\title{
Functional MRI and intraoperative brain mapping to evaluate brain plasticity in patients with brain tumours and hemiparesis
}

\author{
F E Roux, K Boulanouar, D Ibarrola, M Tremoulet, F Chollet, I Berry
}

\begin{abstract}
Objective-To support the hypothesis about the potential compensatory role of ipsilateral corticofugal pathways when the contralateral pathways are impaired by brain tumours.

Methods-Retrospective analysis was carried out on the results of functional MRI (fMRI) of a selected group of five paretic patients with Rolandic brain tumours who exhibited an abnormally high ipsilateral/ contralateral ratio of activation-that is, movements of the paretic hand activated predominately the ipsilateral cortex. Brain activation was achieved with a flexion extension of the fingers. Statistical parametric activation was obtained using a $t$ test and a threshold of $p<0.001$. These patients, candidates for tumour resection, also underwent cortical intraoperative stimulation that was correlated to the fMRI spatial data using three dimensional reconstructions of the brain. Three patients also had postoperative control fMRI.
\end{abstract}

Results-The absence of fMRI activation of the primary sensorimotor cortex normally innervating the paretic hand for the threshold chosen, was correlated with completely negative cortical responses of the cortical hand area during the operation. The preoperative fMRI activation of these patients predominantly found in the ipsilateral frontal and primary sensorimotor cortices could be related to the residual ipsilateral hand function. Postoperatively, the fMRI activation returned to more classic patterns of activation, reflecting the consequences of therapy.

Conclusion-In paretic patients with brain tumours, ipsilateral control could be implicated in the residual hand function, when the normal primary pathways are impaired. The possibility that functional tissue still remains in the peritumorous sensorimotor cortex even when the preoperative $f M R I$ and the cortical intraoperative stimulations are negative, should be taken into account when planning the tumour resection and during the operation.

(F Neurol Neurosurg Psychiatry 2000;69:453-463)

Keywords: brain tumour; functional MRI; brain plasticity; cortical stimulation
Since the works of Penfield and Boldrey ${ }^{1}$ and Foerster ${ }^{2}$ intraoperative cortical stimulation to precisely map brain functions has proved to be useful, especially in infiltrative tumours in or near eloquent areas. ${ }^{34}$ Using optical imaging, Haglund $e t a \bar{l}$ demonstrated the reliability and the accuracy of this method to map function precisely. This technique has become a standard method for localising language and sensory motor cortex in patients during neurosurgical procedures. ${ }^{67}$ Use of this technique is, however, restricted to patients who undergo open brain surgery. In paretic patients, the existence of completely negative stimulations of the hand area normally innervating the paretic limb, ${ }^{7}$ and possibly related to plasticity phenomena, ${ }^{8}$ has seldom been documented by functional studies. In patients with brain tumours, it has also been shown that functional MRI (fMRI) with blood oxygen dependent (BOLD) contrast was capable of depicting functional areas, ${ }^{9-11}$ providing functional information complementary to the structural studies. Thus, fMRI has been used in patients with brain tumours for surgical planning, ${ }^{1012} 13$ epilepsy surgery, ${ }^{12}{ }^{13}$ and to detect functional reorganisations resulting from structural or functional damage. ${ }^{11} \mathrm{Re}-$ cently, fMRI in paretic patients with brain tumours has shown an abnormally high ipsilateral/controlateral ratio of activation when the subject performs a task with his affected hand-that is, the cortex ipsilateral to the paretic hand activates. ${ }^{14}$ Caramia et $a l,{ }^{15}$ using motor evoked potentials (MEPs), suggested that ipsilateral activation could be suppressed or undetected in the normal brain but could be detected when the contralateral control becomes impaired by a tumour. However, the persistence of movement in the affected hand could also be related to persistant contralateral control that is undetected by the functional studies.

Combining fMRI and cortical stimulation, we tried to support the hypothesis of a potentially compensatory role of ipsilateral control when contralateral routes are ineffective. For this purpose, we studied five paretic patients in whom the lack of fMRI activation seen in the contralateral primary sensorimotor region of the affected hand was correlated with the absence of response with cortical stimulation.

Materials and methods PATIENTS

Five patients (two men; three women; age range 50 to 68 years; median age- 60 years; all 
right handed) presenting with various tumours near or in the motor strip and candidates for a tumour resection were studied. These patients were selected from a larger series of 32 patients with various Rolandic tumours who underwent motor fMRI and cortical and subcortical stimulations at our institution in the past 2 years. These five patients were selected because all of them had a particular pattern of fMRI activation: making a movement with their paretic hand, they activated predominantly or exclusively the ipsilateral hemisphere (abnormally high ipsilateral/contralateral ratio with an increased activity of the ipsilateral hemisphere). Emergence of a rapidly progressive motor weakness was the presenting symptom in these five patients, but epilepsy was also noted in one patient. We used the Canadian neurological score $^{16}$ to evaluate globally the degree of hemiparesis of each patient. More specifically, the motor impairment of the hands in these patients was also assessed by a finger ballistic opposition task and by the Medical Research Council (MRC) scale. ${ }^{17}$ The time required to perform 20 finger oppositions of each hand was recorded and compared. The degree of motor impairment could thus be assessed by the time comparison between both hands. The MRC scale is based on an estimation of the index abduction power, as a gross evaluation of hand motor skill. ${ }^{17}$ The duration of the presenting symptom before the diagnosis was made at the time of surgical intervention ranged from 3 days to 2 weeks.

Patients were also assessed between 6 weeks and 10 weeks after the operation with the Canadian neurological and the MRC scores, and the finger opposition test. Their degree of postoperative impairment or recovery was defined as changes in performance in these tests. Hand motor recovery was arbitrarily defined as an increase of at least 1 point in the MRC score and an improvement of the finger opposition time of the paretic hand versus normal hand. Similarly, postoperative motor impairment was defined as a reduction of at least 1 point of the MRC score and by a deterioration of the finger opposition time of the paretic hand versus normal hand.

FMRI PROCEDURE

Motor task procedure

The task chosen was a flexion and extension of the fingers of the paretic hand. The good cooperation of the patients during the fMRI procedure allowed us to also test the normal hand. This specific task was chosen because of its ability to activate most precisely the precentral

Table 1 Summary of the global assessment of the patients, fMRI performed, clinical evaluations, and intraoperative mapping procedures

\begin{tabular}{|c|c|c|c|c|c|c|}
\hline & \multicolumn{2}{|c|}{$\begin{array}{l}\text { Preoperative } \\
f M R I\end{array}$} & \multirow{2}{*}{$\begin{array}{l}\text { Full preoperative } \\
\text { motor assessment }\end{array}$} & \multirow{2}{*}{$\begin{array}{l}\text { Intraoperative cortical } \\
\text { mapping and } \\
\text { electrocorticography }\end{array}$} & \multirow{2}{*}{$\begin{array}{l}\text { Full } \\
\text { postoperative } \\
\text { motor assessment }\end{array}$} & \multirow{2}{*}{$\begin{array}{l}\text { Postoperative } \\
f M R I\end{array}$} \\
\hline & $P H$ & $\mathrm{NH}$ & & & & \\
\hline 1 & + & Dis & + & + & + & + \\
\hline 2 & + & + & + & + & + & NP \\
\hline 3 & + & + & + & + & + & + \\
\hline 4 & + & + & + & + & + & + \\
\hline 5 & + & + & + & + & + & Dis \\
\hline
\end{tabular}

$\mathrm{NP}=$ Not performed; $\mathrm{PH}=$ paretic hand; $\mathrm{NH}=$ normal hand; Dis=discarded (head motion). gyrus (Brodmann area 4), and sometimes the supplementary motor area. ${ }^{9}$ We chose an fMRI task close to the movement elicited intraoperatively by stimulation (flexion of the fingers). Furthermore, the hand area is functionally important, usually well represented in the motor cortex, and easy to test by direct stimulation. Although the task chosen was easy to perform, all subjects were trained to rehearse the task a few minutes before the procedure. Patients were instructed to do the task as fast as possible, but without (or with minimal) head motion.

\section{fMRI data acquisition}

Patients were positioned in the head coil of a 1.5T Magnetom Vision ${ }^{\circledR}$ MR scanner (Siemens, Erlangen, Germany). Optimisation of the magnetic field was performed with the automatic map-shim procedure to reach a gradient tolerance of $0.001 \mathrm{mT} / \mathrm{m}$. fMRI data were obtained using a GE-EPI single shot sequence $\left(\mathrm{TE}=60 \mathrm{~ms} ; \mathrm{FA}=90^{\circ}\right.$; slice number $=10$, matrix size $=64 \times 64, \quad F O V=200$ $\mathrm{mm}$, slice thickness $=5 \mathrm{~mm}$, distant factor $=0.5$ $\mathrm{mm})$. The 10 slices were positioned parallel to the anterior commissure and the posterior commissure (AC/PC) axis from the base of the brain to the vertex. A staff member was always present near the patient during the acquisitions to control the procedure, to encourage the patient to do the task to the best of their ability, and to ensure that the patient followed the start and stop signals. In fact, the fMRI procedure can be long for this category of patient with hemiparesis and often with high grade tumours. The presence of a staff member throughout the MRI study near the patient was also useful to ensure that the patient had no visible syncinesis of his normal hand when performing the task with the affected hand. During the procedure, the patient alternated epochs of rest and epochs of activation. Each epoch (rest or activation) lasted 30 seconds while 10 images were acquired every 3 seconds. Alternative rest and activation periods were repeated four times; with each the procedure began with a period of rest. Each period was controlled vocally by the headphones.

Four patients also had a control fMRI procedure after their operation with the same task. But because of head motion, one study has to be discarded. Because these control fMRI studies were done only for research purposes, no three dimensional anatomical run was done postoperatively. We considered that it was more acceptable for the patients not to again undergo a 12 minute three dimensional anatomical sequence. Thus, for the postoperative studies, the echo planar images were not realigned on the anatomical ones. All these data are summarised in table 1 .

\section{fMRI data analysis}

The fMRI data were analysed with the Statistical Parametric Map (SPM) 96 software $^{18}$ (Wellcome Department of Cognitive Neurology, London, UK) and performed on a Sun SPARC workstation (Mountain view, CA, USA). The first three images of each run were 


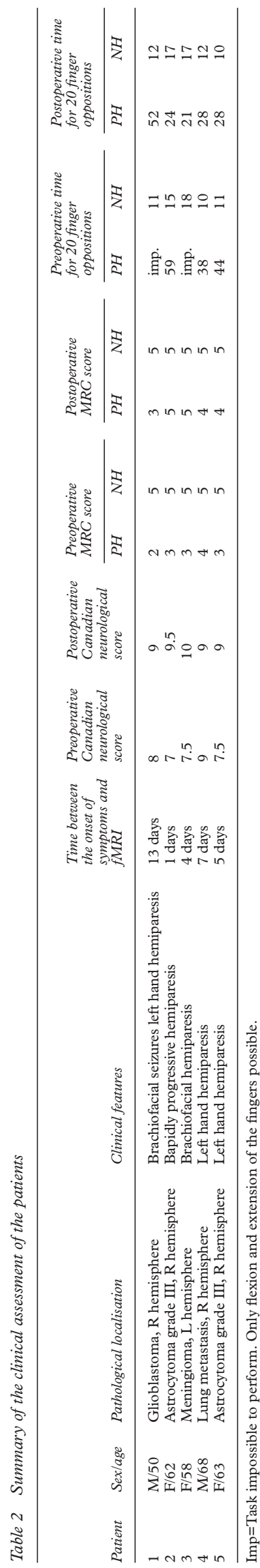

discarded to allow signal stabilisation and the remaining 77 volumes of 10 slices were realigned to correct the subject movement during scanning using the first volume of images as reference. Then the detection of the activated voxels was performed on a pixel by pixel basis. If large movements of the head occurred, the data were excluded from analysis. We used the general linear model implemented in SPM 96 where conditions (rest or activation) stand for independant variables after global normalisation to cancel differences among scans. Usually, voxels were considered as significant if $\mathrm{p}<0.001$, corrected for multiple comparison. In each patient, four regions were studied using reliable sulcal landmarks. The regions studied bilaterally were the primary sensorimotor (S1/M1), frontal (BA 8; BA 9), temporoparietal (BA 40; BA 7; BA 22; BA 39) regions, and supplementary motor regions ( BA 6 ) and the cingular gyrus (BA 24; BA 32). The images were reformatted to be integrated in the radiological atlas of Talairach and Tournoux ${ }^{19}$ using the ANALYZE software (Mayo Clinic, Rochester, MN, USA). The results obtained in both hemispheres were then compared and correlated with cortical brain mapping.

INTRAOPERATIVE CORTICAL STIMULATION PROCEDURE AND CORRELATION

Three dimensional data acquisition

Local distortions of the surface of the gyri produced by the tumour were found on three dimensional reconstructions. This allowed preoperative and intraoperative computer assisted assessment of the relations between the tumour and the important landmarks of gyral anatomy. The surfaces of the brain were reconstructed from a three dimensional data set obtained with a 3D-MPRAGE sequence $\left(\mathrm{TR}=15 \mathrm{~ms} ; \mathrm{TE}=7 \mathrm{~ms} ; \mathrm{FA}=12^{\circ}\right.$; 128 partitions; FOV $=300 \mathrm{~mm}$; matrix size $=256 \times 256$, slab thickness $=150 \mathrm{~mm}$, voxel size $=1.17 \times 1.17 \times 1.17 \mathrm{~mm}^{3}, \mathrm{NA}=1$, $\mathrm{TA}=10$ minutes). The centre of the three dimensional block was positioned according to the AC/PC plane. These three dimensional sequences lasted 12 minutes each. We used the ANALYZE ${ }^{\circledR}$ software (Mayo clinic, Rochester, MN, USA) to separate the brain from the overlying skull and scalp. The 120 slices of the three dimensional data set were usually edited in 90 to 120 minutes.

\section{Cortical stimulation procedure}

Patients were intubated and operated on under general anaesthesia using propofol infusion and $50 \%$ nitrous oxide in oxygen with supplemental $1 \%$ isoflurane and fentanyl (without muscle relaxant). A large craniotomy was often required to ensure that the whole Rolandic region could be studied by cortical stimulation.
The anatomical images were analysed with three dimensional views of the surface of the brain. The central sulcus was found using the three dimensional reconstructions of the surface of the brain. Intraoperative cortical stimulation was used to localise the hand area and eventually other areas of functional cortex in the Rolandic cortex after determination of the afterdischarge threshold. The cortex was directly stimulated using a bipolar Ojemann cortical stimulator ( $1 \mathrm{~mm}$ electrodes separated by $5 \mathrm{~mm}$ :Radionics ${ }^{\circledR}$, Burlington, USA), with an appropriate current to try to elicit a specific movement (flexion of the fingers). The current amplitude was progressively increased by 1 $\mathrm{mA}$ beginning at $1 \mathrm{~mA}$. We used a standard procedure of stimulation with biphasic square wave pulses of $1 \mathrm{~ms}$ at $60 \mathrm{~Hz}$, with a maximum train duration of 4 seconds. Electrocorticography was used to determine the afterdischarge threshold. When a functional site was found, it was marked by a sterile ticket of $0.25 \mathrm{~cm}^{2}$ and then another area $5 \mathrm{~mm}$ away was tested. The exact locations of functional sites were compared with the three dimensional reconstructions of the brain surface and marked on these reconstructions. We studied the whole area exposed during craniotomy by cortical and subcortical mapping as well. Our policy was to spare the functional areas found by this test during the tumour removal by resecting the tumorous tissue no more than $1 \mathrm{~cm}$ from eloquent cortex (distance of the resection margin from the nearest functional site). When no functional site was found, especially in the presumed hand area, our policy was to spare the precentral and postcentral gyri. Intraoperative photographs of the brain were taken with the sites of positive or negative cortical stimulation. The data were analysed by visual comparison of both surface renderings and views of the operative fields. The exact locations of the functional areas were integrated on the three dimensional brain surface renderings by using anatomical landmarks on the brain's surface (gyral and sulcal pattern). Because of the shape and the location of the craniotomy, direct stimulation of some areas (especially the supplementary motor area and cingular gyrus) was not always possible, making the validation by direct stimulation of these areas difficult.

\section{Results}

CLINICAL FINDINGS

Clinical presentations of our patients at the onset of their hemiparesis as well as at the time of their postoperative assessment are summarised in table 2. The MRC and finger opposition scores showed that all our patients were severely impaired before the operation. Two of them (patients 1 and 3) were unable to perform the finger opposition task.

FMRI RESULTS

From 15 fMRI studies (10 preoperative and five postoperative), two studies had to be discarded because of excess motion (the study of the normal hand of patient 1 and the control study of patient 5 . In patient 2 , the control 
Table 3 Number of significantly $(p<0.001)$ activated voxels in the paretic hand of each patient before and after operation

\begin{tabular}{|c|c|c|c|c|c|c|c|c|c|}
\hline & \multirow[b]{2}{*}{ Hemisphere } & \multicolumn{2}{|c|}{$\begin{array}{l}\text { Primary sensorimotor } \\
\text { area }(S 1, M 1)\end{array}$} & \multicolumn{2}{|c|}{ Frontal regions } & \multicolumn{2}{|c|}{ Temporoparietal regions } & \multicolumn{2}{|c|}{$\begin{array}{l}\text { Supplementary motor } \\
\text { area and cingular gyru }\end{array}$} \\
\hline & & Before op & After op & Before op & After op & Before op & After $o p$ & Before op & After op \\
\hline \multirow[t]{2}{*}{1} & Ipsilateral & 89 & 0 & 140 & 29 & 38 & 0 & 147 & 0 \\
\hline & Contralateral & 0 & 114 & 0 & 14 & 0 & 0 & 90 & 0 \\
\hline \multirow[t]{2}{*}{2} & Ipsilateral & 110 & NP & 48 & $\mathrm{NP}$ & 11 & $\mathrm{NP}$ & 11 & $\mathrm{NP}$ \\
\hline & Contralateral & 0 & NP & 13 & NP & 0 & NP & 16 & NP \\
\hline \multirow[t]{2}{*}{3} & Ipsilateral & 47 & 6 & 30 & 8 & 5 & 0 & 5 & 5 \\
\hline & Contralateral & 0 & 34 & 12 & 0 & 0 & 0 & 0 & 11 \\
\hline \multirow[t]{2}{*}{4} & Ipsilateral & 87 & 0 & 32 & 9 & 10 & 4 & 2 & 25 \\
\hline & Contralateral & 0 & 31 & 14 & 4 & 0 & 16 & 2 & 19 \\
\hline \multirow[t]{2}{*}{5} & Ipsilateral & 56 & Dis & 17 & Dis & 9 & Dis & 19 & Dis \\
\hline & Contralateral & 0 & Dis & 0 & Dis & 0 & Dis & 12 & Dis \\
\hline
\end{tabular}

$\mathrm{Op}=$ Operation; $\mathrm{NP}=$ not performed; Dis=discarded.

study of the paretic hand was also not performed because we decided not to do the fMRI procedure, the patient being too tired after the anatomical control MRI runs. No significant foci of increased activation were found within the tumours.

\section{Paretic hand}

In this group of patients the most common regions with increased activation were in the unaffected hemisphere, especially in the primary sensorimotor areas, but also in the frontal and medial areas. Ipsilateral activation was not exclusive and contralateral activation to the paretic hand was also seen individually and to a lesser degree, especially in frontal and medial areas. A strong ipsilateral/contralateral ratio in the sensorimotor area has been found in each patient. In four patients (patients 1, 3, 4, and 5 ), we found no controlateral primary sensorimotor area activation to the paretic hand. Patient 2 had only four activated pixels in his primary sensorimotor area contralateral to the paretic hand. These data are summarised in table 3.

\section{Normal hand}

The activations were found predominantly in the contralateral, unaffected hemisphere and were in agreement with the classic pattern of hand activation. They were located principally in the contralateral primary sensorimotor area (mean of the activated pixels in the primary sensorimotor 227). In three patients (patients 2,3 , and 4), no activated pixels were found in the ipsilateral primary sensorimotor area (affected hemisphere). All patients had a high contralateral/ipsilateral ratio, individually very

Table 4 Number of significantly $(p<0.001)$ activated voxels in the normal hand of each patient before the operation

\begin{tabular}{|c|c|c|c|c|c|}
\hline & Hemisphere & $\begin{array}{l}\text { Primary } \\
\text { sensorimotor } \\
\text { regions }(M 1 / S 1)\end{array}$ & $\begin{array}{l}\text { Frontal } \\
\text { egions }\end{array}$ & $\begin{array}{l}\text { Temporoparietal } \\
\text { regions }\end{array}$ & $\begin{array}{l}\text { Supplementary } \\
\text { motor area and } \\
\text { cingular gyrus }\end{array}$ \\
\hline \multirow[t]{2}{*}{1} & Ipsilateral & 5 & 0 & 0 & 8 \\
\hline & Contralateral & 230 & 45 & 0 & 0 \\
\hline \multirow[t]{2}{*}{2} & Ipsilateral & 0 & 0 & 0 & 17 \\
\hline & Contralateral & 147 & 13 & 0 & 7 \\
\hline \multirow[t]{2}{*}{3} & Ipsilateral & 0 & 6 & 0 & 12 \\
\hline & Contralateral & 143 & 0 & 19 & 0 \\
\hline \multirow[t]{2}{*}{4} & Ipsilateral & 0 & 0 & 0 & 7 \\
\hline & Contralateral & 192 & 0 & 0 & 5 \\
\hline \multirow[t]{2}{*}{5} & Ipsilateral & 3 & 4 & 0 & 0 \\
\hline & Contralateral & 98 & 30 & 0 & 11 \\
\hline
\end{tabular}

different from the ratio found when the contralateral, paretic hand was tested. These data are summarised in table 4 .

\section{Control fMRI}

Four patients (patients 1, 3, 4, and 5) had an fMRI after their operation. In patient 5 , the images had to be discarded because of movement artifacts. For these control fMRI only the paretic hand was tested. In patient 1 , harbouring a right hemispheric glioblastoma and who had a partial recovery of his hand, the control fMRI done 2 months after the operation showed the return of a classic contralateral primary sensorimotor activation with no ipsilateral activation (figs 1 and 2). These findings were probably related to motor recovery of the patient and to elimination of the mass effect. Patient 3 presenting with a meningioma underwent a control fMRI 6 weeks after her operation that also showed a contralateral primary sensorimotor activation to the former paretic hand. In patient 4, fMRI showed a significant change in the location of the activations when compared with the previous ones. This fMRI has been done 8 weeks postoperatively. A contralateral activation in the primary sensorimotor area was again visible with a less important ipsilateral/contralateral ratio.

\section{Cortical stimulation results and fMRI correlation} The whole region of the craniotomy has been studied carefully by bipolar stimulation, repeating the stimulations at least twice for each site. In each patient we progressively increased the level of the stimulation intensity because the amount of current that elicits a hand movement is variable individually and cannot be predicted. In our patients no movement of the affected hand was recorded even at the highest level of stimulation (16 mA) but in one patient this caused a brachiofacial seizure that resolved with application of cold Ringer's lactate to the cortex. It is possible to find responses elicited at higher stimulus intensities, but this is not without risk and we tried to avoid any suprathreshold stimuli because it can result in current spread, neural fatigue, or cell habituation. In this group of patients, we were unable to elicit any hand movement by cortical stimulation. If no hand movement was found, direct cortical stimulation produced flexion of the elbow 


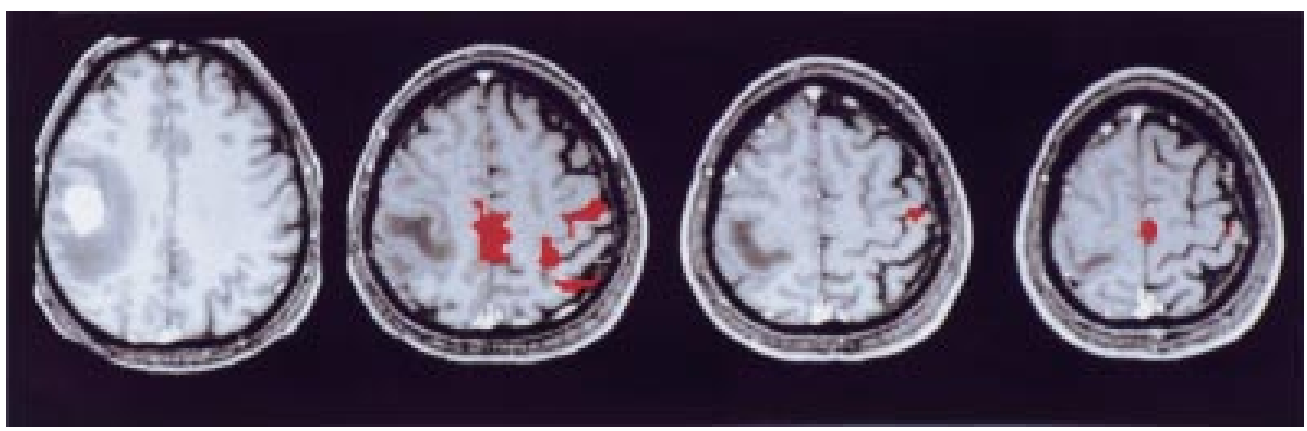

Figure 1 Patient 1. A 50 year old patient presenting with a right glioblastoma and severe left hemiparesis. He was unable to do the finger ballistic opposition task but flexion and extension of the fingers was still possible. Preoperative fMRI done 13 days after the onset of the symptoms (brachiofacial seizures and rapidly progressive hemiparesis) realigned on the anatomical slices (significant threshold: $p<0.001$ ). Paretic hand studied with $f M R I$ during flexion and extension of the fingers. The activations were localised in the ipsilateral sensorimotor cortex and in the supplementary motor areas. No activation in the controlateral primary sensorimotor area can be seen. This finding was confirmed by the cortical brain mapping done intraoperatively.

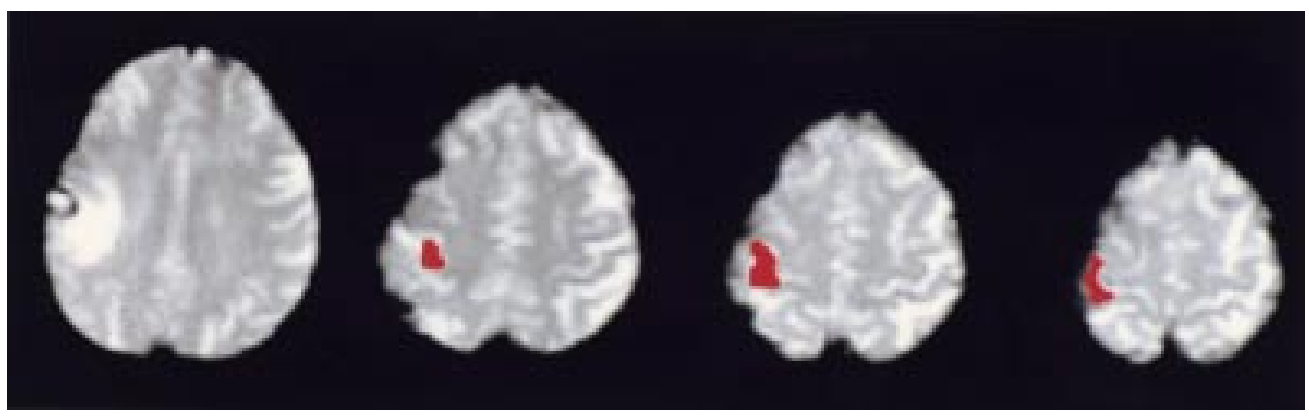

Figure 2 The same patient as in fig 1 and the same task but with fMRI done 2 months after the operation. The patient had a partial recovery of his left hand (finger opposition task done slowly-52 seconds $v 12$ seconds for the normal hand). Left hand studied with $f M R I$ during flexion and extension of the fingers (significant threshold: $p<0.001$ ). This $f M R I$ study was done only for research purposes, and for the comfort of the patient (the three dimensional anatomical sequence lasting 12 minutes), no three dimensional anatomical run was done postoperatively; the echo planar images have thus not been realigned on the anatomical ones. The pattern of activation is now more classic with an activation of the controlateral sensorimotor area while the patient is performing the task. No activation can be seen in the ipsilateral cortex. Some artefacts due to the operation are visible on the periphery of the operated hemisphere.

$(\mathrm{n}=1)$, abduction of the shoulder $(\mathrm{n}=3)$, and contraction of the controlateral face $(n=2)$ (figs 3 and 4). This last movement was often difficult to see because of the operative position of the patient (head turned on the head rest, masked by the drapes). We found no movement in the lower limbs, and no attempt was made to expose the leg cortical areas.

Thus, the absence of fMRI activation in the primary sensorimotor area of the affected hemisphere was associated, in each patient, with a negative cortical stimulation (impossible to elicit any hand movement even with high intensities). Postoperatively, partial or total recovery was related to significant changes in the fMRI studies (figs 5, 6, 7, and 8).

\section{Discussion}

Combining preoperative and postoperative fMRI and cortical stimulation in a selected group of patients with hemiparesis and brain tumour, we demonstrated (a) that the lack of fMRI activation seen in the contralateral primary sensorimotor area of the affected hand was correlated with the absence of response with cortical stimulation; $(b)$ that this fact presumes that the hand area in the affected hemisphere was not functional or masked; $(c)$ that the residual hand function was probably related to the ipsilateral activation seen with fMRI; $(d)$ and that these phenomena could be rapidly seen after the onset of symptoms (a few days), could be temporary, and that an absence of detection of a functional tissue by fMRI or cortical stimulation did not imply that viable functional tissue was present in the peritumorous brain. Our results are in agreement with those of Yoshiura et al, who used fMRI in seven patients with brain tumours and found that the ratio of the ipsilateral/contralateral activated hand was abnormally high in three paretic patients. ${ }^{14}$ Caramania et al used MEPs in seven patients with various brain tumours and in volunteers. ${ }^{15}$ Not all their patients had motor deficits but they found, comparing the results with healthy subjects, that ipsilateral MEPs were generally absent in normal subjects but present in the patients by stimulating the nonaffected hemisphere. These findings could be related to a potential compensatory role of the ipsilateral motor control.

METHODOLOGICAL ISSUES

They are many methodological issues related to the use of fMRI in patients with brain tumours. Technical problems such as echoplanar distortion, paradigm choices, movement artifacts, and venous effects have been evoked in many fMRI studies. ${ }^{90-22}$ But more specific problems must be recognised when using the fMRI technique in patients with brain tumours. It is in these particular conditions that 


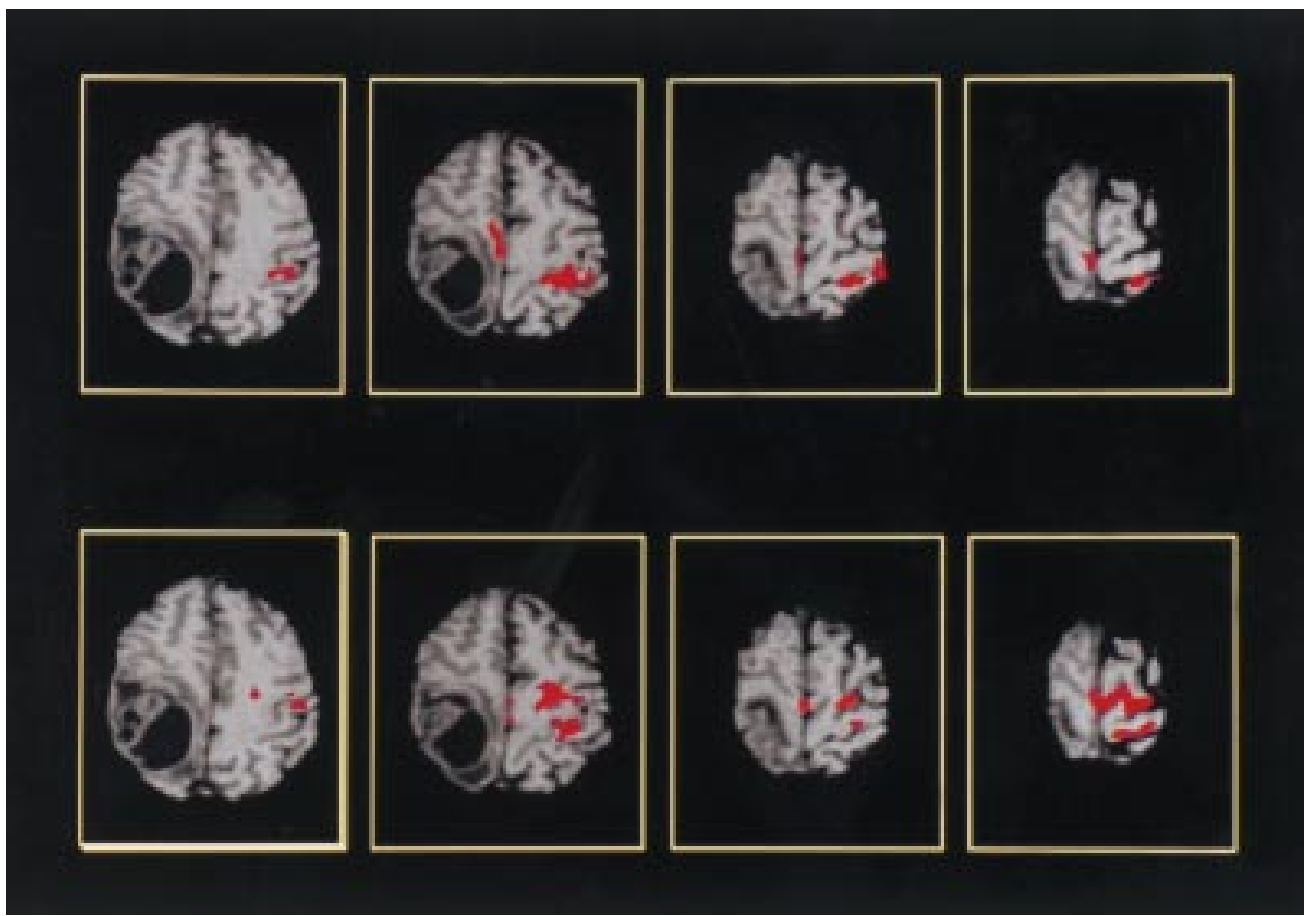

Figure 3 Illustrative case of the spatial distribution of the ipsilateral activated area in the intact hemisphere. Patient 2 presenting with an astrocytoma grade III (WHO classification). She had fMRI 24 hours after the onset of her symptoms (a rapidly progressive left hemiparesis). The left paretic hand (below) and right normal hand (top) studied with fMRI during flexion and extension of the fingers (significant threshold: $p<0.001$ ). Functional images realigned on the anatomical ones. The recruited ipsilateral cortical area and the activated area of the normal hand in the intact hemisphere are in the same region. Most of the ipsilateral activation is located in the Rolandic zone and there is a certain degree of overlapping between both areas.

the validation of fMRI data is the most useful. The most appropriate statistical methodology in the analysis of fMRI data in neurosurgical patients has not yet been defined. The rate and the amplitude of the paradigm vary and influence $^{21}$ the amount and volume of brain activation obtained. The area of activation is

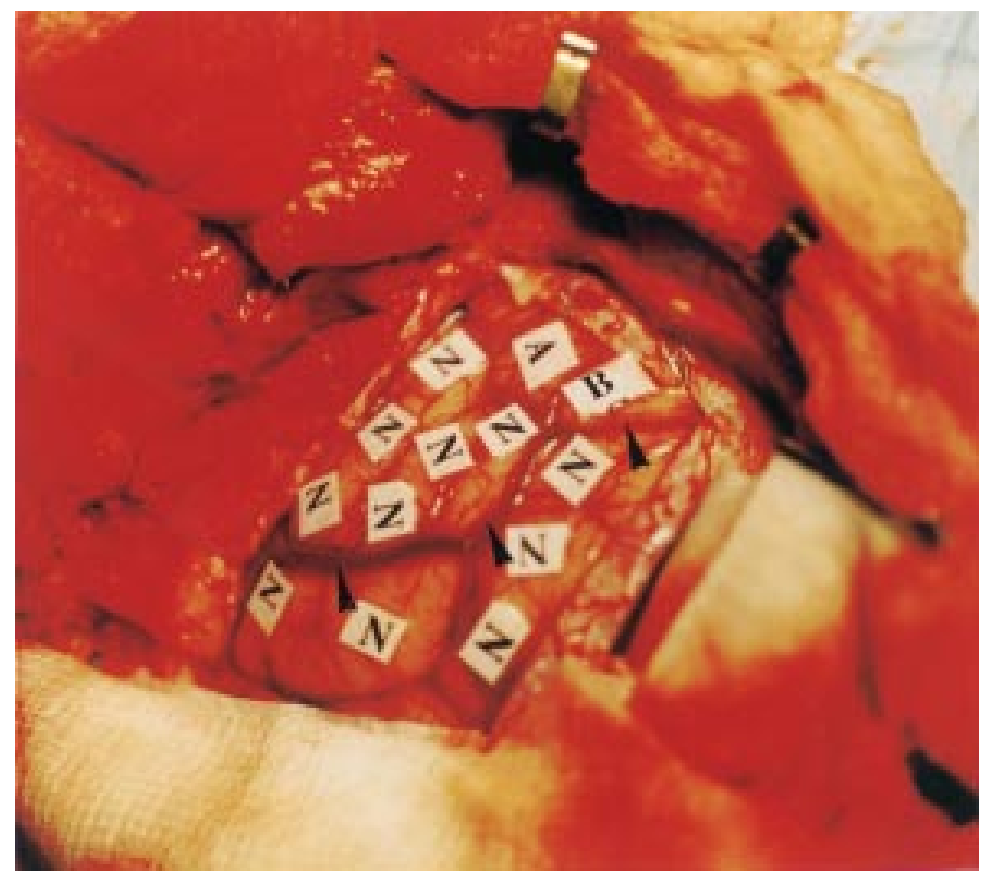

Figure 4 Patient 2. Intraoperative view of the cortex after brain mapping and before tumour removal. Bipolar stimulation did not identify sites that elicited a flexion of the fingers but abduction of the controlateral shoulder was seen $(A)$ as well as flexion of the elbow (B). Negative sites for a motor response are marked $N$. Arrows=the central sulcus. also related to the specialisation of the cerebral structure studied. ${ }^{23}$. These factors can make the analysis of fMRI data extremely difficult. Therefore relations between neuronal activity, local cerebral blow flow, and cerebral tumour (especially in high grade astrocytoma) in fMRI remain unclear. ${ }^{23}$ The significance thresholds chosen to generate activation maps of a function are arbitrary and it is precisely the discrepancy between this statistical map and the true map of a function that requires validation. It could be argued that the arbitrary threshold chosen was too strict and that there might have been activations at a lower level of significance. The usefulness of intraoperative cortical mapping is that it can validate the statistical maps given by the analysis of fMRI. It was particularly true in our patients where the absence of activation in the primary sensorimotor area of the affected hemisphere has to be validated by another technique.

NEUROANATOMICAL ASPECTS

Türck first described in 1851 the pyramidal tract, extending from the motor cortex to the spinal cord. $^{24}$ In 1909, Holmes and May showed that the pyramidal tract arose from the precentral gyrus. ${ }^{25}$ But others have shown that the pyramidal fibres originate from various cortical areas, including the precentral gyrus, and also the premotor cortex, the primary sensory cortex, the parietal associative cortex, and the supplementary area. ${ }^{26}$ At the junction of the medulla and the spinal cord, most of the fibres cross the midline in the pyramidal decussation 


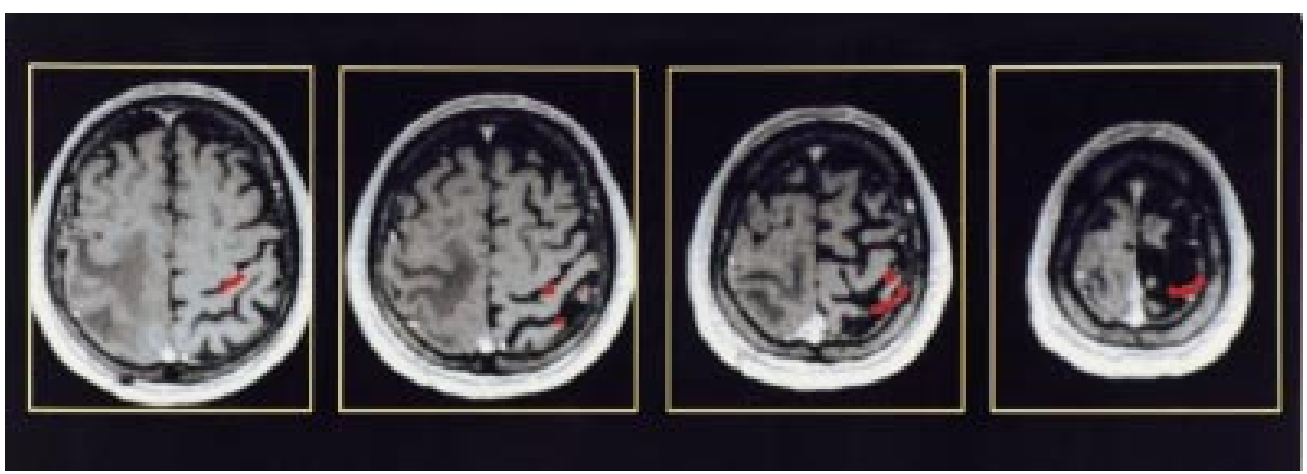

Figure 5 Patient 4. Paretic left hand studied with fMRI during flexion and extension of the fingers (significant threshold: $p<0.001)$. The patient presenting with a lung metastasis in the right hemisphere. Most of the activation is situated in the ipsilateral hemisphere, in the Rolandic area.

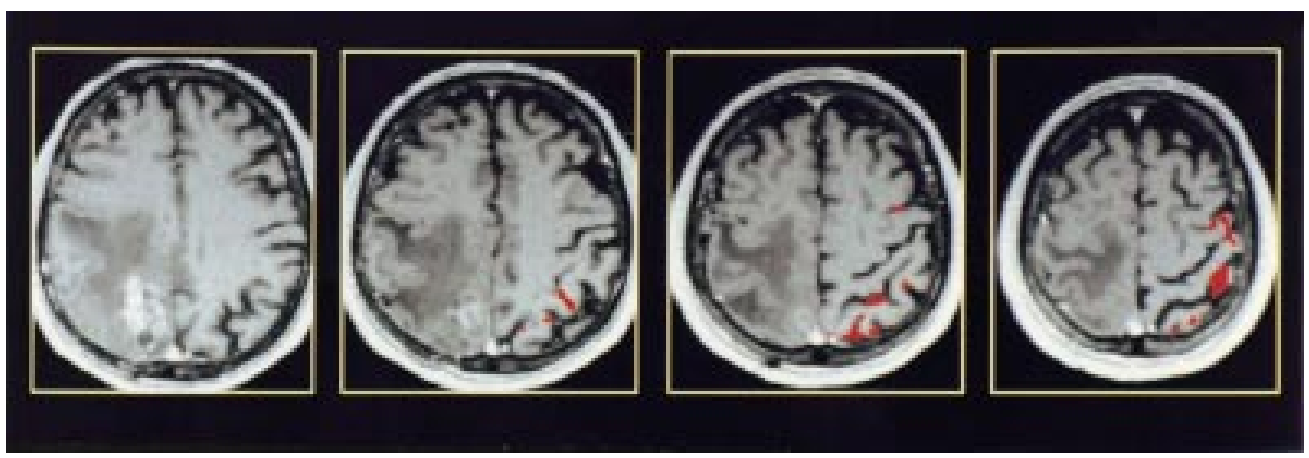

Figure 6 Patient 4. Normal right hand activated area. fMRI during flexion and extension of the fingers (significant threshold: $p<0.001)$. Classic pattern of activation with the Rolandic area of the intact hemisphere predominantly activated.

to form the lateral corticospinal tract whereas uncrossed fibres form the ventral corticospinal tract or remain in the lateral corticospinal tract. ${ }^{26}$ Ipsilateral pyramidal fibres seems to represent $10 \%$ to $25 \%$ of the total fibres, ${ }^{26}$ although quantitative assessment is difficult and probably varies individually. The ventral corticospinal tract projects bilaterally to the ventromedial motor neuron pools innervating axial and proximal muscles as well as to the

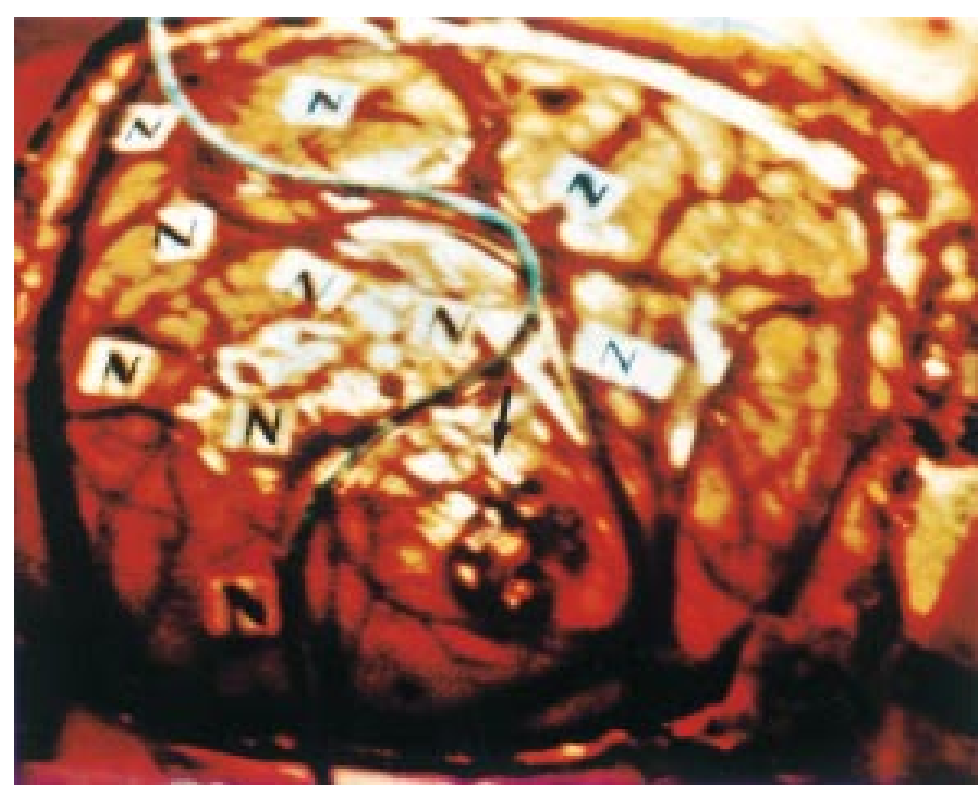

Figure 7 Patient 4. Intraoperative view showing the post-Rolandic tumour (arrow). Bipolar stimulation with $16 \mathrm{~mA}$ did not identify sites that elicited a flexion of the fingers. The whole area of craniotomy has been studied. $N=$ Negative sites for hand motor response; thread=the central sulcus. These findings are correlated with the fMRI data showing no activation in the controlateral Rolandic area of the paretic hand (fig 5). adjoining portions of the intermediate zone of the grey matter of the spinal cord. It originates principally in Brodmann's area 6 and in the Brodmann's area 4 in zones controlling the neck and trunk. ${ }^{26}$ The anatomical existence of an ipsilateral pyramidal tract can support the hypothesis of the partial contribution in the residual movement in paretic patients or partipation in recovery from stroke or tumours, ${ }^{27}$ but this hypothesis must be supported by functional studies.

INTRAOPERATIVE CORTICAL STIMULATION, FMRI CORRELATION, AND CLINICAL OUTCOME

Data from fMRI has been recently validated prospectively by SEPs, ${ }^{20}$ electric transcranial stimulations ${ }^{28}$ magnetoencephalography, ${ }^{28}$ and direct intraoperative stimulation ${ }^{29}$ often in a few patients and principally in motor areas. Although cortical mapping identifies only those eloquent brain areas that are on the surface of the brain, it is still considerated as the gold standard of brain mapping. ${ }^{671030}$ All authors have emphasised the good spatial correlation existing between fMRI and this technique. In the primary sensorimotor areas, several authors ${ }^{28-30}$ have shown that functional activated MRI areas were related to a positive electrostimulation response and that when no activation was found on fMRI, no response was found intraoperatively by electrostimulation. We also found in our patients, by the usual methods of electrostimulation, that the absence of fMRI activation in a given area was correlated with the absence of response.

Some criticism could arise about the spatial correlation between fMRI and cortical stimula- 


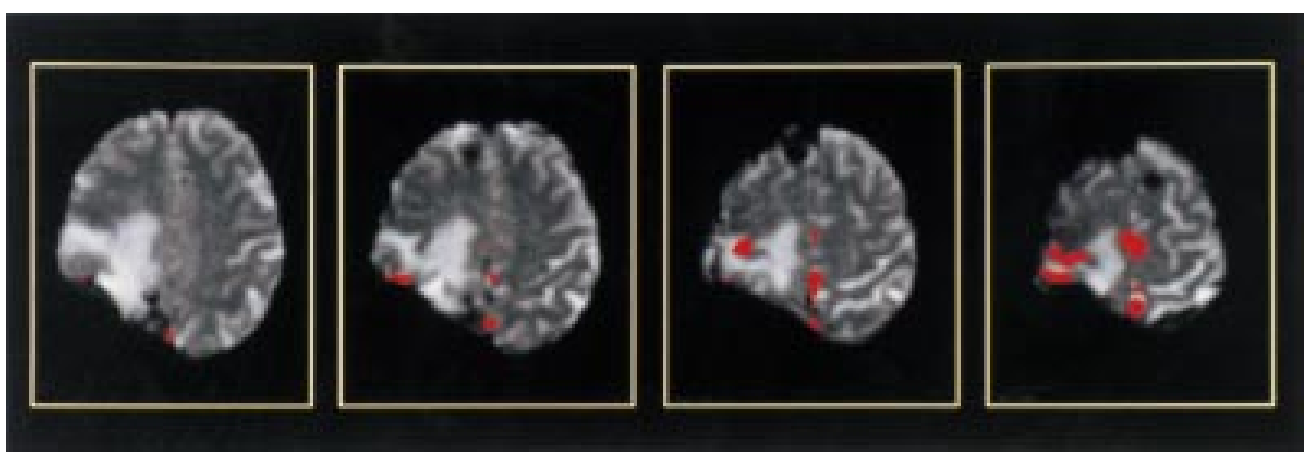

Figure 8 Patient 4 postoperative fMRI of the left hand (former paretic hand). $f M R I$ during flexion and extension of the fingers (significant threshold: $p<0.001$ ). fMRI done 8 weeks postoperatively. This $f M R I$ study was done only for research purpose, and for the comfort of the patient (the three dimensional anatomical sequence lasting 12 minutes), no three dimensional anatomical run has been done postoperatively; the echo planar images were thus not realigned on the anatomical ones. Note the echo planar artefacts in the operated zone. Compare with the fMRI done preoperatively. It is the same patient, the same task, and the same procedure of analysis of the images but the tumour has been removed and the patient's hand, although still impaired, is less paretic than preoperatively.

tion, especially how to know, intraoperatively, that the cortical area found by stimulation matches spatially the fMRI activated areas. This point could be an issue in our patients. The use of visual inspection of both three dimensional surface renderings and operative fields by using anatomical landmarks on the brain's surface to correlate our data has already been used by others. ${ }^{29} 3132$. This method has proved to be reliable and accurate ${ }^{29}$ although the use of a technique of functional image guided surgery in which motor fMRI imaging is registered to an infrared based frameless stereotactic device should improve the localisation. ${ }^{33}$

The second point is the possibility of finding no motor response in the motor strip by electrical stimulation. This possibility has been reported in other series. ${ }^{74} 35$ The first explanation is that no motor function is present in this area, precluding any motor response. This is probably the case in our paretic patients. Mass effect and local invasion can lead to loss of function. The time frame in which a local neuronal area becomes non-functioning or destroyed is not well known. Skirboll and Ojemann, ${ }^{34}$ using direct cortical stimulation, found that functional tissue can be present in the boundaries of an invasive tumour without loss of function initially. In fMRI, several authors found that an activated area can be located in the peritumorous brain, ${ }^{9}{ }^{10} 29$ corroborating the findings of Skirboll and Ojemann. ${ }^{3}$ The progressive nature of tumours can explain the potential reorganisation phenomena described by some authors. It seems that a critical level of neuronal infiltration or destruction must be reached for a deficit to be seen clinically. ${ }^{3}$ If cortical invasion can be a cause of loss of function, a mass effect by disruption or stretching of the pyramidal tracts can also be involved. In these circumstances, where a tumour has been resected, there can be rapid improvement in motor function (and even full recovery) caused by the decompressive effect of the surgery. ${ }^{8} 36$ This implies that, in some paretic patients, negative motor stimulation does not mean that no function is potentially present in the area tested. We found this phenomenon in three of our patients (patients 1,3 , and 4 ) where we were able to have a postoperative MRI. All of our patients recovered postoperatively, although this recovery was partial in three of them (patients 1, 4, and 5).

If cortical reorganisation can depend on temporal factors, tumour location can also play a part. If no motor response is seen in the motor strip, that can mean that hand area is possibly displaced because of the tumour. This had already been noticed by Penfield and Boldrey. ${ }^{1}$ Seitz et al, studying six patients with low and high grade tumours, suggested that the tumour location was predictive of the direction of the functional shift and the degree of functional compensation. ${ }^{8}$ The functional shift, either ventrally or dorsally in the function of the maximal tumour growth, could explain some negative cortical stimulation found. ${ }^{8}$ Other conditions of negative stimulation include acute brain swelling and too small a craniotomy to expose the motor strip. ${ }^{7}$

\section{FUNCTIONAL ASPECTS}

Ipsilateral movements have been found in patients with cortical stimulation, although not often. ${ }^{1}$ Cortical stimulation using MEPs in humans has been associated with motor responses in ipsilateral fingers. ${ }^{37}$ Ipsilateral activation has been also reported with fMRI in normal subjects. ${ }^{38} 39$ Compared with the controlateral side, the activation was smaller and weaker. ${ }^{38}$ The ipsilateral primary sensorimotor cortex can also be significantly implicated in complex movements. ${ }^{39}$ In paretic patients, care must be taken in the analysis of fMRI data. With only five patients, our series was limited but the ipsilateral activation seen was clearly different from the activations usually found in normal subjects; firstly, because our patients showed no controlateral activation of the primary sensorimotor area and secondly because the ipsilateral activations seen were more important that the activations usually found in normal subjects.

Sparse data are available to show whether severe motor deficit reduces the probability of finding focal activity in the motor cortex and what type of relation can be established between the degree of motor deficit and fMRI 
activation. Previous functional studies report a widespread hand activity in paretic patients. ${ }^{40}$ Furthermore, activations of the ipsilateral cortex, of the supplementary motor area, and of prefrontal areas in patients with motor deficits more often than in intact patients have been reported by several authors. ${ }^{27} 4041$ Atlas et al have hypothesised that it may be a quantifiable difference on fMRI between the tumour bearing cortex and the normal hemisphere that could be related to the extent of the patient deficit. ${ }^{9}$ In patients with cerebral vascular malformations, Schlosser et al showed that gross neurological deficits were always present when the activated cortex was displaced to a new anatomical location. ${ }^{42}$ This displacement of functions has been described in some chronic neurological diseases potentially related to functional recovery. ${ }^{43}{ }^{44}$ But it can also be found in strokes ${ }^{27} 45$ and was recently described in tumours. ${ }^{42} 46$ Displacement of function, increase of the activated hand area, and ipsilateral activation seem to be the mecanisms decribed by most authors. However, care must be taken in the analysis of this last effect because of the potential effect of the handedness on the activations. Kim et al and $\mathrm{Li}$ et al, using fMRI in volunteers, have reported a degree of ipsilateral activation greater during the performance of left hand tasks than during right hand tasks, especially in right handers. ${ }^{47} 48$ However, this phenomenon seems to occur to a lesser degree with motor tasks than with sensory tasks. ${ }^{48}$ Another problem is that we cannot completely rule out associated movement of the hand ipsilateral to the tumour although we were physically present during the fMRI procedure to ensure that the patient have no synkinesis of his normal hand. EMG recordings were not made in our patients. Subclinical associated movements of the normal hand have been noted in paretic patients. ${ }^{40}$

Aberrant mapping of cortical function has been well described in the developing brain. ${ }^{43}$ The underlying mecanisms proposed to sustain brain plasticity are collateral axonal sprouting, unmasking of pre-existing areas due to desinhibition, ${ }^{49}$ and contribution of the ipsilateral hemisphere through the direct pyramidal pathway $^{27}$ or via transcallosal connections. In our patients with acquired lesions, the ipsilateral activations seen are probably related to the unmasking mecanism. Patient 2, for instance, had her fMRI 24 hours after the onset of hemiparesis. It would be unlikely that sprouting with consequent formation of new synaptic contact had occurred. The possibility of finding no function in the primary controlateral motor cortex in patients able to sustain residual motor activity and then to find an activated area in the primary motor cortex on control fMRI after the operation suggests a temporary disinhibition mechanism. Disinhibition of pre-existing but normally weak or non-functional synaptic connections, not ordinarily shown by standard electrophysiological assays, could be the substrate for short term changes occuring after interruption of the major motor pathways. ${ }^{50} 51$ The disinhibition mechanism leading to an increase of activation in an adjacent motor region has been well described by Jacobs and Donoghue. ${ }^{52}$ Corticospinal neurons projecting to proximal muscles in an overlap region may be disinhibited ${ }^{535}$ explaining the shift of a cortical functional area in lesions of the pyramidal tract. $^{86}$ This phenonenon can occur within hours of a peripheral nerve lesion. ${ }^{55}$ The ipsilateral activation in paretic patients with brain tumours could be due to the same mecanism of desinhibition.

The spatial distribution of the ipsilateral activated area in the intact hemisphere must also be discussed. Most of our ipsilateral activation was located in the Rolandic zone and there was a certain degree of overlapping between both areas. This finding has been underlined by others. ${ }^{37456}$ Huttenlocher and Raichelson found that the ipsilateral and controlateral pyramidal tract originate from the same areas in rats that had undergone neonatal hemispherectomy. ${ }^{56}$ Meagaki et $a l,{ }^{44}$ using MEPs in a case of unilateral extensive cortical dysplasia, found that the abductor pollicis brevis response of the paretic and controlateral side originated from the same motor cortex. The fact that ipsilateral hand representation lies in the primary motor cortex was also described by Wasseramn et al. ${ }^{37}$

As we demontrated previously in patients after stroke, ${ }^{27} 57$ our results suggest that the ipsilateral corticofugal pathways in paretic patients are able to sustain not only proximal but also distal residual activity without recourse to the controlateral primary motor areas. But this ipsilateral activation in paretic patients with a brain tumour leads to some questions: are the findings explained in terms of reorganisation or are the paretic patients just trying harder to do the movement? It has been shown that a certain degree of ipsilateral activation can be seen in complex movement or in patients doing some movement requiring a more important force. ${ }^{58} \mathrm{~A}$ movement, becoming more complex or stronger, requires the participation of proximal muscles to stabilise the joints. These proximal muscles are more bilaterally represented in the cortex ${ }^{26}$ than distal hand muscles and the ipsilateral activations could be partially explained by the recruitment of these more proximal muscles in a patient trying to do the movement at best. This fact can also be supported by the EMG study of Turton et al that in patients after stroke, ipsilateral responses from the unaffected hemisphere were most prevalent in the proximal muscles of the affected limb. ${ }^{59}$

\section{Conclusion}

Ipsilateral activation has been described with fMRI in normal subjects. In patients with motor deficits, activations of the ipsilateral cortex, of the supplementary motor area, and of prefrontal areas have also been reported more often than in intact patients. ${ }^{974041}$ These displacements of functions seen in fMRI possibly relate to brain plasticity phenomena ${ }^{42}$ and need to be validated by other methods. In our patients and for the specific hand tasks used, the absence of primary sensorimotor activation was correlated with negative cortical stimula- 
tion. Disinhibition of pre-existing but normally weak or non-functional synaptic connections could be the mechanism implicated in the ipsilateral activations seen in our patients. However, in paretic patients with Rolandic tumours, the possibility of finding no primary sensorimotor activation in the peritumorous brain would not imply that no functional tissue is potentially present even with a negative hand cortical area stimulation. This should be taken into account in the presurgical evaluation of the functional tissue surrounding a tumour in paretic patients with fMRI.

1 Penfield W, Boldrey E. somatic motor and sensory represenstimulation. Brain 1937;60:389-443.

2 Foerster O. The motor cortex in man in the light of Hughlings Jackon's doctrine. Brain 1936;59:135-59.

3 Ojemann JG, Miller JW, Silbergeld DL. Preserved function in brain invaded by tumor. Neurosurgery 1996;39:253-9.

4 Skirboll SS, Ojemann GA, Berger MS, et al. Functional cortex and subcortical white matter located within gliomas. tex and subcortical white mater

5 Haglund MM, Ojemann GA, Blasdel GG. Optical imaging of bipolar cortical stimulation. F Neurosurg 1993;78:78593.

6 Berger MS, Kincaid J, Ojemann GA, et al. Brain mapping techniques to maximize resestion, safety and seizure control in children with brain tumors. Neurosurgery 1989;25:786-92.

7 Ebeling U, Schmid UD, Ying $\mathrm{H}$, et al. Safe surgery of lesions near the motor cortex using intra-operative mapping techniques: a report on 50 patients. Acta Neurochir (Wien) 1992;119:23-8.

8 Seitz RJ, Huang Y, Knorr U, et al. Large-scale plasticity of the human motor cortex. Neuroreport 1996;6:742-4.

9 Atlas SW, Howard II RS, Maldijian J, et al. Functional magnetic resonance imaging of regional brain activity in patients with intracerebral gliomas: findings and implicapatients with intracerebral gliomas: findings and implica38 .

10 Roux FE, Boulanouar K, Ranjeva JP, et al. Usefulness of motor functional MRI correlated to cortical mapping in rolandic low-grade astrocytoma. Acta neurochir (Wien) 1999;140:71-9.

11 Fandino J, Kollias SS, Wieser HG, et al. Intraoperative validation of functional magnetic resonance imaging and cortical reorgaization patterns in patients with brain tumor involving the primary motor cortex. F Neurosurg 1999;91 238-50.

12 Latchaw RE, Hu X. Functional MR imaging in the evaluation of the patient with epilepsy. Functional localization. Neuroimaging Clin N Am 1995;5:683-93.

13 Stapleton SR, Kiriakopoulos E, Mikulis D, et al. Combined utility of functional MRI, cortical mapping and frameless stereotaxy in the resection of lesions in eloquent areas of brain in children. Pediatr Neurosurg 1997;26:68-82.

14 Yoshiura T, hasuo K, Mihara F, et al. Increased activity of the ipsilateral motor cortex during a hand motor task in the ipsilateral motor cortex during a hand motor task in 1997; 18:865-9.

15 Caramia MD, Telera S, Palmieri MG, et al. Ipsilateral motor activation in patients with cerebral gliomas. Neurology 1998;51:196-202.

16 Côté R, Hachinski VC, Shurvell BL, et al. The Canadian neurological scale: a preliminary study in acute stroke. Stroke 1986;17:731-7.

17 Bastings EP, Rapisarda G, Pennisi G, et al. Mechanisms of hand motor recovery after strokes: an electrophysiologic study of central motor pathways. F Neurorehab 1997;11:97108 .

18 Friston KJ, Holmes AP, Worsley KJ, et al. Statistical parametric maps in functional imaging: a general appoach. Hum Brain Mapp 1995;2:189-210.

19 Talairach J, Turnoux P. Co-planar stereotactic atlas of the human brain. New York: Thieme Medical, 1988.

20 Puce A, Constable RT, Luby ML, et al. Functional magnetic resonance imaging of sensory and motor cortex: comparison with electrophysiological localization. I Neurosurg 1995;83:262-70.

21 Rao SM, Bandettini PA, Binder JR, et al. Relationship between finger movement rate and functional magnetic resonance signal change in human primary motor cortex. $f$ Cereb Blood Flow Metab 1996;16:1250-4.

22 Segebarth C, Belle V, Delon C. Functional MRI of the human brain: predominance of signals from extracerebral veins. Neuroreport 1994;5:813-16

23 Sergent J. Brain-imaging studies of cognitive functions. TINS 1994;17:221-7.

24 Türck L. Uber secundäre erkrankung einzlner rückenmarkstränge und ihrer fortsetzung zum gehirne. SB Akad Wiss Wein $1851 ; 6: 288$.

25 Holmes GL, May WP. On the exact origin of the pyramidal tracts in man and other mammals. Brain 1909;32:1-42.

26 Kuypers HG. Anatomy of the descending pathways. In: VB Brooks, ed. Handbook of physiology, section 1: the nervous sys- tem. Vol II. Motor control. Bethesda: American Physiological Society, 1981;597-666.

27 Cholet F, DiPiero V, Wise RJ, et al. The functional anatomy of motor recovery after stroke in humans: a study with positron emission tomography. Ann Neurol 1991;29:63-71.
Morioka T, Mizushima A, Yamamoto T, et al. Functional mapping of the sensorimotor cortex: combined use of magnetoencephalography, functional MRI, and motor evoked potentials. Neuroradiology 1995;37:526-30.

29 Jack CR, Thompson RM, Butts RK, et al. Sensory motor cortex: correlation of presurgical mapping with functional MR imaging and invasive cortical mapping. Radiology 1994;190:85-92.

30 Krings T, Buchbinder BR, Butler WE, et al. Functional magnetic resonance imaging and transcranial stimulation: complementary approches in the evaluation of cortical motor function. Neurology 1997;48:1406-16.

31 Yetkin FZ, Mueller WM, Morris G, et al. Functional MR activation correlated with intraoperative cortical mapping. Am 7 Neuroradiol 1997;18:1311-15.

32 Fried I, Nenov VI, Ojemann SG, et al. Functional MR and PET imaging of rolandic and visual cortices for neurosurical planning. F Neurosurg 1995;83:854-61.

33 Schulder M, Maldijian JA, Liu WC. Functional imageguided surgery of intracranial tumors located in or near the sensorimotor cortex. F Neurosurg 1998;88:412-18.

34 Gregory EM, Goldring S. Localization of function in the excision of lesions from the sensorimotor cortex. $\mathcal{F}$ Neurosurg 1984;61:1047-54.

35 King RB, Schell GR. Cortical localization and monitoring during cerebral operations. F Neurosurg 1987;67:210-19.

36 Lüders HO, Comair YG, Bleasel AF, et al. Recovery of function following lesions of eloquent brain areas. In: Freund HJ, Sabel BA, Witte OW, eds. Brain plasticity, advance in neurology. Philadelphia: Lippincott-Raven, 1997;73:33546.

37 Wassermann EM, Pascual-Leone A, Hallett M. Cortical representation of the ipsilateral hand and arm. Exp Brain Res 1994;100:121-32.

38 Kim SG, Alshe J, Georgopoulos AP, et al. Functional imaging of the human motor cortex at high magnetic field. $\mathcal{F}$ Neurophysiol 1993;69:297-302.

39 Shibasaki H, Sadato N, Lyshkow H, et al. Both primary motor cortex and supplementary motor area play an mportant role in complex finger movement. Brain 1993;116:1387-98.

40 Weiller C, Ramsay SC, Wise RJ, et al. Individual patterns of functional reorganization in the human cerebral cortex after capsular infarction. Ann Neurol 1993;33:181-9.

41 Werring DJ, Clark CA, Barker GJ, et al. The structural and functional mechanisms of motor recovery: complementary use of diffusion tensor and functional magnetic resonance imaging in a traumatic injury of the internal capsule. $\mathcal{F}$ Neurol Neurosurg Psychiatry 1998;65:863-9.

42 Schlosser MJ, McCarthy G, Fulbright RK, et al. Cerebral vascular malformations adjacent to sensorimotor and visual cortex. Functional MRI studies before and after therapeutic intervention. Stroke 1997;28:1130-7.

43 Cao Y, Vikingstad EM, Huttenlocher PR, et al. Functional magnetic resonance studies of the reorganization of the human hand sensorimotor area after unilateral brain injury in the perinatal period. Proc Natl Acad Sci USA 1994;91:9612-16.

44 Maegaki Y, Yamamoto T, Takeshita K. Plasticity of central motor and sensory pathways in a case of unilateral extensive cortical dysplasia. Neurology 1995;45:2255-60.

45 Cramer SC, Nelles G, Benson RR, et al. A functional MRI study of subjects recovered from hemiparetic stroke. Stroke 1997:28:2518-27.

46 Wunderlich G, Knorr U, Herzog H, et al. Precentral glioma location determines the displacement of cortical hand representation. Neurosurgery 1998;42:18-27.

$47 \mathrm{Kim}$ SG, Alshe J, Hendrich K, et al. Functional magnetic resonance imaging of motor cortex: hemispheric asymmetry and handedness. Science 1993;261:615-17.

$48 \mathrm{Li}$ A, Yetkin Z, Cox R, et al. Ipsilateral hemisphere activation during motor and sensory tasks. AfNR Am f Neuroradiol 1996;17:651-5.

49 Jones RD, Donalson IM, Parkin PJ. Impairement and recovery of ipsilateral sensory-motor function following unilateral cerebral infarction. Brain 1989;112:113-32.

50 Netz J, Lammers T, Homberg V. Reorganization of motor output in the non-affected hemisphere after stroke. Brain 997;120:1579-86.

51 Zarzecki P, Witte S, Smits E, et al. Synaptic mechanisms of cortical representational plasticity: somatosensory and corticocortical EPSPs in reorganized raccoon SI cortex. 7 Neurophysiol 1993;69:1422-32.

52 Jacobs KM, Donoghue JP. Reshaping the cortical motor map by unmasking latent intracortical connections. Science 1991;251:944-7.

3 Cohen LG, Roth BJ, Wasserman EM, et al. Magnetic stimulation of the human cerebral cortex, an indicator of reorganization in motor pathways in certain pathological conditions. F Clin Neurophysiol 1991;8:56-65.

54 Levy WJ, Amassian VE, Schimd UD, et al. Mapping of motor cortex gyral sites non-invasively by transcranial magnetic stimulation in normal subjects and patients. In: Levy WJ, Cracco RQ, Barker AT, et al, eds. Magnetic motor stimulation: basic principles and clinical experience (EEG suppl). Amsterdam: Elsevier, 1991.

55 Sanes J, Donoghue J. Organization and adaptability of muscle representation in the primary motor cortex. Exp Brain Res 1992;22(suppl):103-7. 
56 Huttenlocher PR, Raichelson RM. Effects of neonatal hemispherectomy on location and number of corticospianl neurons in the rat. Dev Brain Res 1989;47:59-69.

57 Marque $\mathrm{Ph}$, Felez A, Puel M, et al. Impairement and recovery of left motor function in patients with right hemiplegia. F Neurol Neurosurg Psychiatry 1997;62:77-81.
58 Dettmers C, Fink GR, Lemon RN, et al. Relation between cerebral activity and force in the motor areas of the human cerebral activity and force in the motor
brain. $\mathcal{I}$ Neurophysiol 1995;74:802-15.

59 Turton A, Wroe S, Trepte N, et al. Controlateral and ipsilateral EMG responses during recovery of arm and hand function after stroke. Electroencephalogr Clin Neurophysiol 1996;101:316-28.

\section{HISTORICAL NOTE}

The fissure of Sylvius (1614-72)

Franciscus called Sylvius, was a descendant of a protestant family named $\mathrm{Du}$ Bois (changed to de le Boël$^{1}$ ) from Cambrai, in France. For religious reasons the family moved to Germany. Sylvius was born in Hanau, Germany. He read medicine at the universities of Sedan and Leiden. He began his studies in June, 1632 at Leiden and offered a disputation Positiones variae medicae in 1634. Sylvius obtained his medical doctorate at the University of Basel on 16 March 1637, defending a thesis De animali motu ejusque laesionibus. According to Haller this is the first description of the lateral cerebral fissure. This fissure and the cerebral aqueduct were not fully described by Sylvius until $1663 .{ }^{1}$

He practised for a short period but graduated again at Leiden University in November 1638. His skills in teaching anatomy brought him respect and a certain fame: "many students, and certainly not the worst ones, attended his courses, so that it seemed as if only he could understand and explain anatomy."

One of these students was Thoma Bartholini, son of the famous Danish anatomist Caspar Bartholini. In the 1641 edition of his well known textbook Institutiones anatomicae published by Thoma, 12 years after Caspar's death, it is clear that Caspar with Sylvius had shown and named the cerebral fissure separating the temporal lobe from the frontal lobe above. ${ }^{2}$ Not until 1663 was it separately published in Sylvius's Opera as Disputationes medicarum ad C Bartholini Institutiones Anatomicas, but Caspar Bartholini gave credit to Sylvius for the discovery, probably in his thesis of 1637 .

After this important work, Sylvius turned his attention to the circulation. He was able to show that the blood had an independent flow or circulation through the blood vessels, pumped by the heart. Thus, he tried to convince his seniors of the medical faculty that Harvey's theory was correct. Professor Johan Walaeus, one of his professors, became a spirited proponent of Harvey's theory. Sylvius had proposed the circulation in the lungs in his thesis of 1634, 6 years after De motu cordis.

Sylvius moved from Leiden to Amsterdam in 1641 . He practised there for 17 years, until in 1658 he returned to Leiden as Professor of
Medicine. He gave his inaugural lecture $D e$ Hominis Cognitione on 17 September. He was an excellent and enthusiastic teacher and lecturer, concentrating on the more common ailments prevalent at the time in the Caecilia Hospital. He applied the Socratic method and emphasised the modern systems of diagnosis, prognosis, and therapy. His work shows the importance he attached to necropsies as a way of verifying or rejecting clinical diagnoses, as well as giving clues as to the nature of the disease. It is Sylvius who is said to have first demonstrated at necropsy the lung tubercles.

Sylvius became interested in iatrochemistry, a concept that sought to explain physiological processes as dependent on chemical mechanisms; the idea was not far removed from modern neurotransmitters. Of the theses presented under his presidency, one named Disputationem medicarum decas 1(1663), contained "the primary natural functions of the human body deduced from anatomical, practical and chemical experiments." Sylvius regarded as fundamental the effervescence or violent reaction, between acid and alkaline secretions and he rejected the classic humours. But he retained the notion of the animal spirits. These spirits in the blood were transported by the neck arteries in the capillaries on the brain surface in a process analogous to distillation. The most spiritual part of the blood passed the pores of capillaries, first in the grey matter and then in the white matter.

Because of his brilliance, clinical teaching in Leiden flourished under Sylvius and attracted many students from many other countries. When he died on 15 November 1672 , the medical faculty of Leiden went into a relative state of decline.

Sylvius published his pathology under the title Praxeos medica idea nova. Unfortunately, he could only complete the first volume (1671). His former pupil Justus Schrader posthumously published the other volumes, including the appendix. Generally speaking, diseases were caused by abnormal effervescence due to abnormal secretions, which could be either sharp alkaline or sharp acidic. A defective animal spirit resulting from an accumulation of a volatile acid spirit, for instance, caused epilepsy. Therapy consisted of the prescription of alkaline salts, opposing the action of the excess of acid.

His contributions to the anatomy of the brain were recognised by Thomas Bartholinus, who in 1640 remarked:

"we can not pass over in silence the very accurate anatomist D. Franciscus Sylvius, since we borrow from his noble brain and ingenuity the admirable new structure of the brain."
His works in neuroanatomy were published in the disputation De spirituum animalium in cerebro, cerebelloque confectione, per nervos distributione, atque usu vario, defended by the student Gabriel Ypelaer under Sylvius's supervision in 1660. The lateral fissure of Sylvius is described:

" . . the surface of the cerebrum is very deeply marked by twistings (gyri) which are somewhat similar to convolutions of the small intestine. Particularly noticeable is the deep fissure or hiatus which ... begins at the roots of the eyes(oculorum radices) . . .it runs posteriorly above the temples as far as the origin of the brain stem (medullae radices) ... .It divides the cerebrum into an upper, larger part and a lower, smaller part. Twistings occur along the fissure's length and depth even with the origins of smaller convolutions at the most superior part of it." (1663, pp 43-44.)

Sylvius's accurate study of the outer surface of the brain was done because of his interest in the vascular system on the brain surface, and his interest in the grey matter related to the animal spirits.

\section{The ventricular aqueduct}

The connection between the third and fourth ventricles had already been mentioned or supposed by Galen in De usum partium as a canal giving communication between the cerebrum and the cerebellum. Vesalius had described in the Fabrica (1543) an "anus-like orifice of the meatus which extends from the third to the fourth ventricle" below the quadrigeminal bodies. In chapter 21 in the disputation of Franciscus Sylvius is described a canalis vel aquae-ductus between the conjoined roots of the spinal cord and under "our bridge" (pons Varoli) and the corpora quadrigemina. The aqueduct was certainly known before Sylvius, and both Haller and Morgagni were critical of naming the aqueduct after Franciscus Sylvius.

The naming of the fissure followed Thomas Bartholini's homage to Sylvius's work, but it had been described by Caspar Bartholini.

J M S PEARCE

304 Beverley Road, Anlaby, Hull HU10 7BG, UK

Correspondence to: jmspearce@freenet.co.uk

1 Sylvius F. (de la Boë) Disputationes medicarum pars prima. Amstelodami, van den Bergh, 1663. Cited by: McHenry LC. Garrison's History of neurology. Springfield, Illinois: Charles C Thomas 1969:64.

2 Bartholin C. Institutiones anatomicae, novis recentiorum opinionibus and observationibus quarum inmumerae hactemus editae non sumt, figurisque innumerae hactenus editae non sunt, figurisque Batavorum, Apud Franciscum Hackium, 1641. 